\title{
Expression and promoter methylation of the RASSF 1A gene in sporadic breast cancers in Chinese women
}

\author{
YONGMEI LI*, QINJUN WEI*, FANG CAO and XIN CAO \\ Department of Biotechnology, Nanjing Medical University, \\ Nanjing 210029, P.R. China
}

Received August 22, 2007; Accepted November 7, 2007

\begin{abstract}
The novel tumor suppressor RASSF $1 A$ is frequently inactivated during human tumorigenesis by promoter methylation. In this study, we detected the RASSF $1 A$ promoter methylation by methylated-specific PCR and investigated RASSF 1A gene expression by semi-quantitative RT-PCR and immunohistochemical staining in 36 cases of breast cancer and their adjacent normal tissues in Chinese women. The promoter methylation of the RASSF 1A gene was found to be a frequent event in the breast cancers $(61.1 \%)$. RASSF $1 A$ methylation was not found in the matched adjacent normal tissues. The loss frequency of RASSF $1 A$ mRNA was $33.3 \%$ and that of the RASSF1A protein was $44.4 \%$ in breast cancers. RASSF1A mRNA and protein were all expressed in adjacent normal tissues. The mRNA and protein expression level of RASSF1A was significantly lower in breast cancer than in adjacent normal tissue. However, the promoter methylation of the RASSF1A gene in breast cancers were not correlated with clinical parameters, such as ages, histological types, TNM stages and lymph node metastases. Thus, the promoter methylation of RASSF1A was one reason for the low level of RASSF1A mRNA and protein expression and was a frequent event in primary sporadic breast tumorigenesis in Chinese women.
\end{abstract}

\section{Introduction}

The Ras association domain family 1 (RASSF 1$)$ gene is located at 3 p21.3 with a frequent loss of heterozygosity and homozygosity in a variety of human tumors. The RASSF 1 locus encodes two major transcripts and several tissue-specific

Correspondence to: Dr Xin Cao, Department of Biotechnology, Nanjing Medical University, Nanjing, Jiangsu 210029, P.R. China

E-mail: caoxin@njmu.edu.cn

${ }^{*}$ Contributed equally

Abbreviations: RASSF1, Ras association domain family 1; MSP, methylated-specific PCR

Key words: methylation, breast cancer, Ras association domain family $1 \mathrm{~A}$ splice variants, the most commonly detected being RASSF 1A and $-C$. RASSF1A and $-C$ proteins contain a Ras association domain. RASSF1A also contains a diacylglycerol-phorbolester binding domain near its $\mathrm{NH}_{2}$ terminus (1-4). Loss of expression of the RASSF1A isoform is a frequent event in primary human tumors and the re-expression of RASSF1A in human tumor cell lines inhibits their tumorigenic phenotype (5). Moreover, knock-out mice, defective for RASSF1A, are prone to tumor development (6). It has been concluded that RASSF $1 A$ is a tumor suppressor that plays a key role in the development of human cancer. Inactivation of RASSF $1 A$ in human tumors typically occurs via promoter methylation (6-8). RASSF $1 A$ methylation occurs in a broad spectrum of carcinomas and other solid tumors. In several types of tumors, RASSF $1 A$ is inactivated at a high frequency, ranging from 40 to $50 \%$ in breast, prostate, and ovarian cancer to $30-80 \%$ in lung tumors and $>90 \%$ in renal cell carcinomas (9). RASSF1A is probably the most frequently methylated gene described thus far in human cancer.

Different conclusions have been drawn about promoter methylation and the expression of RASSF1A in breast cancer (10-12) and some research has been done on the RASSF1A gene in breast tumors in Chinese women (13). We investigated 36 sporadic breast cancer cases and adjacent normal tissues in Chinese women. MSP (methylated-specific PCR), semiquantitative RT-PCR and immunohistochemical staining were used to investigate the promoter methylation status and expression of RASSF1A gene in these tissues.

\section{Materials and methods}

Patient tissue samples and histological classification. The study group consisted of 36 female breast cancer patients aged 24-80 years. The patients were diagnosed at the First Affiliated Hospital of Nanjing Medical University (Jiangsu, China) during 2003-2004 and the patient samples were collected according to the ethics committee of the First Affiliated Hospital of Nanjing Medical University. Primary breast cancers and their nomal tissues $(5 \mathrm{~cm}$ away from the adjacent tumor tissue) were obtained from each of the patients. None of them had received radiotherapy or chemotherapy. All the breast cancer patients were classified according to the World Health TNM criteria (4 of stage I, 17 of stage II, 12 of stage III and 3 of stage IV). Of these patients, 27 developed lymphatic metastasis. Data on tumor 
Table I. The PCR primers and amplification size.

\begin{tabular}{llc}
\hline Primer & \multicolumn{1}{c}{ Primer sequence $\left(5^{\prime} \rightarrow 3^{\prime}\right)$} & Size $(\mathrm{bp})$ \\
\hline RASSFIA (U) & F:5'-GGGGGTTTTGTGAGAGTGTGTTT-3' & 204 \\
& R:5'-CCCAATTAAACCCATACTTCACTAA-3' & 192 \\
RASSFIA (M) & F:5'-CGAGAGCGCGTTTAGTTTCGTT-3' \\
& R:5'-CGATTAAACCCGTACTTCGCTAA-3' \\
RASSF1A & F:5'-CAGATTGCAAGTTCACCTGCCACTA-3' \\
& R:5'-GATGAAGCCTGTGTAAGAACCGTCCT-3' & 249 \\
B-actin & F:5'-AAAGACCTGTACGCCAACAC-3' \\
& R:5'-GTCATACTCCTGCTTGCTGAT-3' & 219 \\
\hline
\end{tabular}

U, unmethylated PCR primers; M, methylated PCR primers.

grade, histological type and lymphatic metastasis of the tumors were obtained from the Department of Pathology in the hospital. The tissues were first placed in liquid nitrogen and then frozen at $-86^{\circ} \mathrm{C}$ until the extraction of total RNA and DNA.

Bisulfite modification. DNA was extracted from breast cancer tissues by standard proteinase $\mathrm{K}$ digestion, phenol chloroform and ethanol precipitation proceeded. The method of bisulfite modification was performed according to previous methods $(14,15)$, with some modifications. DNA $(1 \mu \mathrm{g})$ in a volume of $45 \mu 1$ was denatured by $\mathrm{NaOH}$ (final concentration of 0.3 $\mathrm{mol} / \mathrm{l}$ ) at $37^{\circ} \mathrm{C}$ for $20 \mathrm{~min}$ and then treated with $3 \mathrm{~mol} / \mathrm{l}$ sodium bisulfite $520 \mu \mathrm{l}(\mathrm{pH} \mathrm{5.0)}$ and $10 \mathrm{mmol} / \mathrm{l}$ hydroguinone $30 \mu \mathrm{l}$ at $50^{\circ} \mathrm{C}$ for $16 \mathrm{~h}$. Tumor and control DNA were purified using the Wizard DNA clean-up system (Promega, USA) following the manufacturer's recommendations. The modified DNA was re-suspended in $20 \mu 1 \mathrm{TE}(\mathrm{pH}$ 8.0) and stored at $-20^{\circ} \mathrm{C}$.

Methylation-specific polymerase chain reaction amplication. The primer sequences were determined according to previous reports (5) (Table I). The size of the PCR products for the methylated RASSF 1A promoter was $204 \mathrm{bp}$ and for the unmethylated RASSF1A promoter $196 \mathrm{bp}$. The solution $(25 \mu \mathrm{l})$ contained $50 \mathrm{ng} / \mu 1$ of modified DNA, 10 pmol of each primer, $0.45 \mathrm{mM}$ dNTP, 1.25 units HotStartTaq enzyme mixture supplied with $1 \mathrm{X}$ reaction buffer. The PCR was carried out in a thermocycler (PTC-100 Peltier thermal cycler, USA) under the following conditions: one cycle of $95^{\circ} \mathrm{C}$ for $5 \mathrm{~min}$, followed by 40 cycles of denaturing at $95^{\circ} \mathrm{C}$ for $1 \mathrm{~min}$, annealing at $56^{\circ} \mathrm{C}$ for $1 \mathrm{~min}$ and extension at $72^{\circ} \mathrm{C}$ for $1 \mathrm{~min}$. This was followed by the final extension at $72^{\circ} \mathrm{C}$ for $10 \mathrm{~min}$. The PCR products were analysed by electrophoresis on $2 \%$ agarose gel and samples were evaluated. Methylation was considered positive only when there were obvious bands displayed on the agarose gel.

PCR product sequencing. PCR products were recovered by using a Quick gel extration kit. The ABI PRISM Big Dye Terminator kit was used to perform the direct sequencing. The product of sequencing PCR included $16 \mathrm{CpG}$ sites.
RNA extraction and semi-quantitative $R T-P C R$. The primers of the RASSF1A gene were according to previous reports (1). Total RNAs were isolated from the sample tissues using a TRIzol procedure (Invitrogen, USA). An equal amount of RNA from each sample was added to $20 \mu$ l of reaction mixture and cDNA was synthesized by Rever Tra Ace-@ kit (Toyobo, Japan). PCR was performed using a PCR thermal cycler. The cycle was defined at $95^{\circ} \mathrm{C}$ for $5 \mathrm{~min}$, followed by 35 cycles of denaturing at $95^{\circ} \mathrm{C}$ for $1 \mathrm{~min}$, annealing at $60^{\circ} \mathrm{C}$ for $1 \mathrm{~min}$ and extension at $72^{\circ} \mathrm{C}$ for $2 \mathrm{~min}$. This was followed by the final extension at $72^{\circ} \mathrm{C}$ for $10 \mathrm{~min}$. The size of the RASSF1A gene products was $249 \mathrm{bp}$. For $\beta$-actin gene amplification, the thermal cycle was defined at $95^{\circ} \mathrm{C}$ for $5 \mathrm{~min}$, followed by 27 cycles of denaturing at $95^{\circ} \mathrm{C}$ for $1 \mathrm{~min}$, annealing at $60^{\circ} \mathrm{C}$ for $1 \mathrm{~min}$ and extension at $72^{\circ} \mathrm{C}$ for $2 \mathrm{~min}$. This was followed by the final extension at $72^{\circ} \mathrm{C}$ for $10 \mathrm{~min}$. The size of the $\beta$-actin gene products was $219 \mathrm{bp}$. The PCR products were analysed on $2 \%$ agarose gel.

Immunohistochemistry. A RASSF 1A protein expression analysis was performed on formalin-fixed and paraffinembedded malignant breast tissue and adjacent normal tissue (sliced in $5 \mu \mathrm{m}$ sections), with RASSF1 (N-15) antibody (Santa Cruz, USA). Tissue sections were deparaffinized and stained according to the routine standard procedures. A routine streptavidin-biotin protocol using the SABC kit (SA1023-lgG, Bosten, China) was applied. The tissue sections mounted on glass slides were first incubated in $0.5 \%$ BSA in PBS to reduce non-specific protein binding and then sequentially incubated to react with monoclonal anti-RASSF1A primary antibody (1:200) overnight at $4^{\circ} \mathrm{C}$. For antibody detection all slides were incubated with StreptABComplex/biotin reagents following the manufacturer's recommendations. Biotin sites were visualized with 3,3'-diaminobenzidine (DAB) and counterstaining was performed with hematoxylin. The presence of RASSF1A was detected by light field microscopy as a dark brown reaction product in cytoplasm.

Statistical analysis. Proportions were compared by two-tailed Fisher's exact test. Associations with P-values $<0.05$ were considered to be significant. 


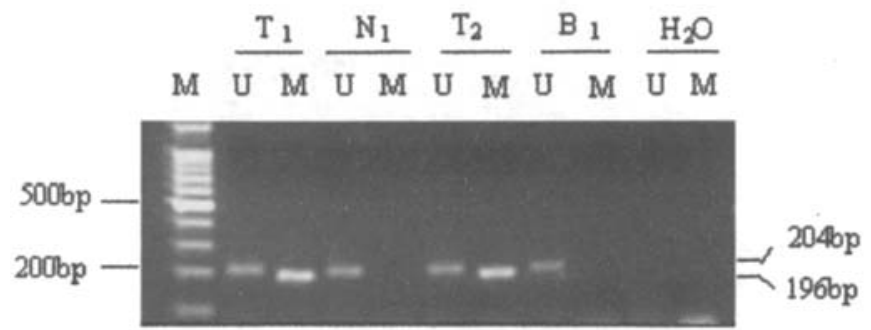

Figure 1. Methylated-specific PCR (MSP) analysis for methylation of the RASSF1A gene promoter in tumors. T1 and T2, breast cancer tissues; N, adjacent normal tissue, $\mathrm{B} 1$, normal tissue; $\mathrm{H}_{2} \mathrm{O}$, negative control; $\mathrm{M}$, methylated and U, unmethylated.

\section{TGGTTTCGTT $\stackrel{\downarrow}{\downarrow}$ GGTTCGCGTTTGTTAGCGTTT: $\$: G T 7$}
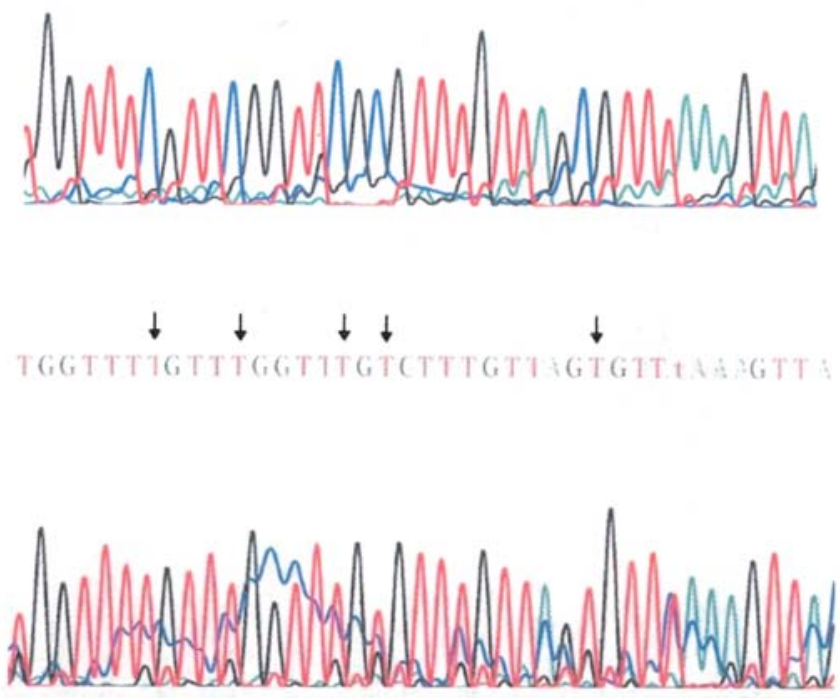

Figure 2. Methylation analysis of RASSF $1 A$ promoter by bisulfite sequencing. Two representative sequences showed the methylation status of cytosines at the target sites of MS-PCR primers. Methylated cytosines found in tumor cases remained unchanged as cytosines after bisulfite modification, whereas unmethylated cytosines were converted and sequenced as thymine.

\section{Results}

Methylation of RASSF1A. The RASSF 1A promoter methylation was assayed using MSP. Genomic DNAs from breast cancer tissues and adjacent normal tissues were amplified by PCR with different primers for methylated and unmethylated DNA, respectively. Twenty-two (66.6\%) of 36 breast cancer tissues showed promoter hypermethylation of RASSF1A. None of the adjacent normal tissues showed promoter methylation (Fig. 1). There was a significant difference in RASSF1A promoter hypermethylation between breast cancer tissues and adjacent normal tissues $(\mathrm{P}<0.05)$. This result suggested the gene promoter methylation was more common in breast cancer than in normal tissues.
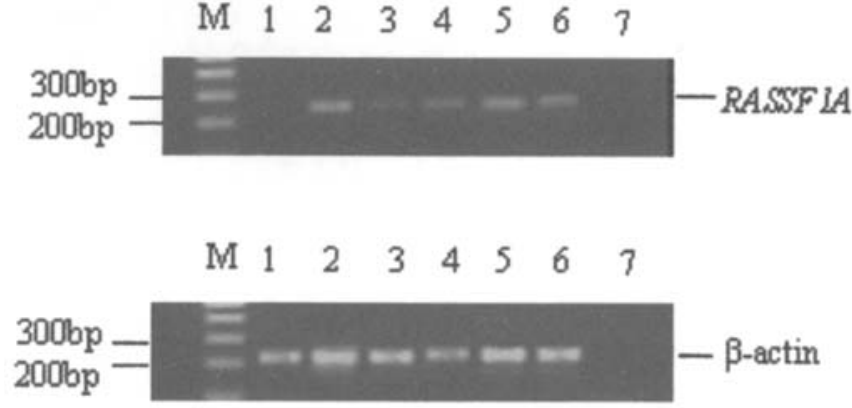

Figure 3. mRNA expression of RASSF1A gene. M, 100 bp DNA standard; 1 and 3 , specimen of breast cancer; 2 and 4, matching adjacent normal tissues; 5 and 6, breast tumors; 7, negative control; upper panel, RASSF $1 A$ and lower panel, $\beta$-actin.

RASSF 1A CpG island sequencing analysis. Bisulfite sequencing analysis (Fig. 2) performed on the breast cancer tissues with fresh-frozen DNA and positive MS-PCR reaction, confirmed that these samples had methylated $\mathrm{CpG}$ islands in tumor tissues but not in the corresponding adjacent normal tissues of breast cancer tissues.

RASSF1A mRNA expression. Twelve cases of 36 breast cancer tissues did not show any detectable mRNA expression of the RASSF1A gene but the adjacent normal tissues all showed mRNA expression of RASSF $1 A$ gene. The mean relative intensity of the mRNA expression of the RASSF $1 A$ gene in breast cancer and adjacent normal tissues was $0.18264 \pm 0.1181$ and $0.5561 \pm 0.2693$, respectively (Fig. 3). The level of mRNA expression of the RASSF 1A gene in breast cancer tissues was significantly lower than in adjacent normal tissues $(\mathrm{P}<0.05)$. Promoter hypermethylation was correlated with inactivation or a low mRNA expression of the RASSF 1A gene.

RASSF1A protein expression. Out of 36 breast cancer tissues, $16(44.4 \%)$ cases did not show a protein expression of the RASSF 1A gene while 10 cases showed a reduced RASSF1A protein expression and the adjacent normal tissues showed RASSF1A protein expression. There was a significant difference in the RASSF1A protein expression between breast cancer and the adjacent normal tissues $(\mathrm{P}<0.05)$ (Fig. 4). Breast cancer tissues (20 out of 22) whose RASSF1A promoter was methylated had a reduced or no RASSF1A protein expression.

Tumor grade and histological type. The frequency of promoter hypermethylation in breast cancer tissues was not correlated with clinical parameters, such as age, histological type, TNM stage and lymph node metastases ( $\mathrm{P}>0.05)$ (Table II).

\section{Discussion}

Biological features of breast cancer are determined by its underlying molecular alterations of the tumor, including the inactivation of tumor suppression genes, as well as mutations and deletions. It is now clear that the de novo promoter hypermethylation is a common mechanism to the inactive tumor suppressor. DNA methylation is one of epigenetic 

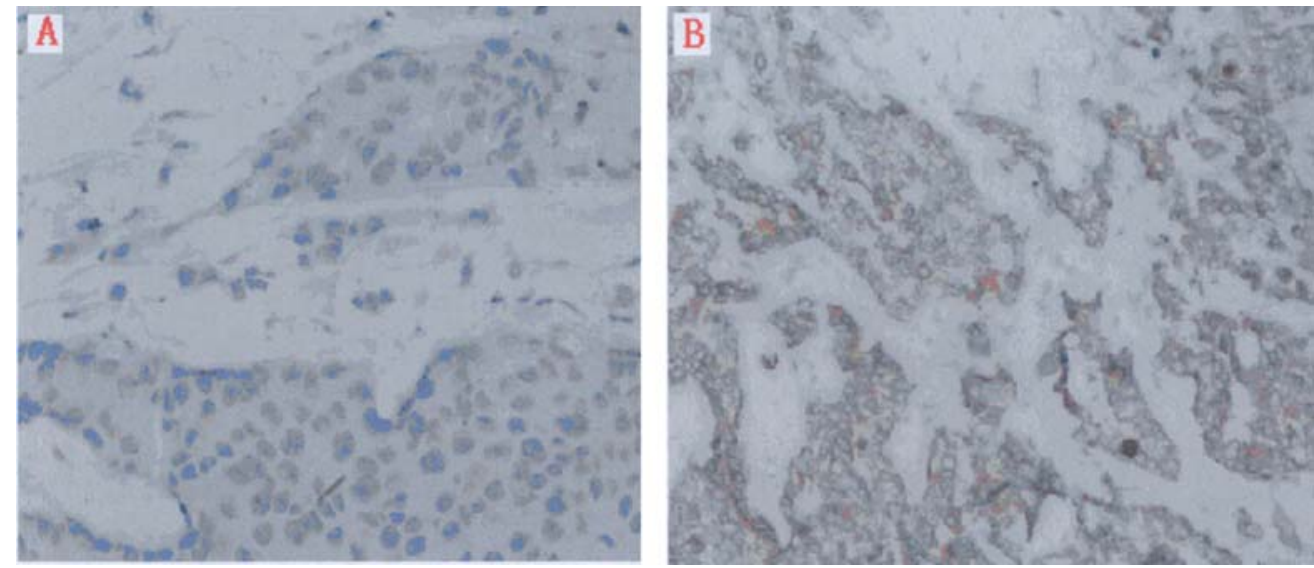

Figure 4. (A) Immunohistochemical expression of RASSF1A in breast cancer tissue, showing a markedly reduced expression of RASSF1A protein. (B) Immunohistochemical expression of RASSF1A in adjacent normal tissues, showing a wild-type expression of the RASSF1A protein.

Table II. The relationship between the promoter methylation of RASSF1A and clinicopathological features.

\begin{tabular}{lcccc}
\hline & Cases & Cases of methylation & Frequency of methylation $(\%)$ & P \\
\hline Age & & & & \\
$\leq 50$ years & 17 & 9 & 52.9 & $>0.05$ \\
$>50$ years & 19 & 13 & 73.5 & $>0.05$ \\
Clinical stage & & & & \\
$\quad$ Stage I & 4 & 2 & 50.0 & $>0.05$ \\
Stage II & 17 & 12 & 70.6 & \\
Stage III & 12 & 2 & 50.0 & \\
Stage IV & 3 & & 66.7 & \\
Histological subtype & & & & \\
Colloid carcinomas & & 1 & 33.3 & \\
Lobular carcinomas & 3 & 21 & 63.6 & \\
Lymph node metastasis & 33 & 18 & 66.7 & $>0.05$ \\
$\quad$ Yes & 27 & 4 & 44.4 & \\
No & 9 & & & \\
\hline
\end{tabular}

modifications (16). It occurs at cytosine bases located 5 ' to a guanosine and so-called $\mathrm{CpG}$ dinucleotide short regions of $\mathrm{CpG}$ dinucleotides known as $\mathrm{CpG}$ islands are found in the proximal promoter region of over half of human genes (17). The methylation of these gene promoters is generally not detected in normal tissues but in the hypermethylation of $\mathrm{CpG}$ islands resulting in a loss of gene function, which is a common feature in many tumor types, including breast cancer.

As an important tumor suppressor gene, RASSF $1 A$ inactivation has been detected in a variety of malignancies and it inactivated at a high frequency. For example, the methylation of RASSF1A is found in $80 \%$ of small cell lung cancers $(7,8)$, in $90 \%$ of hepatocellular carcinomas (19-21) and $>70 \%$ of prostate cancers $(21,22)$. Although data on the methylation of the RASSF $1 A$ gene in breast cancer in some countries $(5,11,12,23)$ exist, we reported here on the methylation status of 36 breast cancers and normal adjacent tissues in Chinese women. It was found that the frequency of the methylation of breast cancers was $61.1 \%$ but none was found in the adjacent normal tissues. The frequency of the promoter methylation in breast cancers was significantly higher than that in normal tissues. Clinical data showed that the gene methylation status of RASSF $1 A$ did not correlate with clinical parameters, such as patient age, histological type, clinical stage and lymph node metastases, indicating that the methylation of RASSF 1A gene is an early molecular change in breast cancer tumorigenesis.

We analysed the mRNA level of RASSF 1A gene in breast cancers using semi-quantitative RT-PCR. Breast cancer tissues had a loss of mRNA expression (33.3\%), however, adjacent normal tissues all showed mRNA expression. Moreover, the level of mRNA expression in breast cancer was significantly lower than that in adjacent normal tissues. This result indicated that the low level or loss of RASSF1A expression played a role in breast cancer development. Dammann et al (8) found that mRNA expression in breast 
cancers decreased significantly as compared to adjacent normal tissues and found that 5 breast cancer cell lines (MCF-7, MDAMB15, MDAMB23, T47 and ZR75-1) indicated a loss of mRNA expression of RASSF1A. The CpG islands and RASSF $1 A$ promoter were completely methylated. Treatment with the DNA methylation inhibitor 5-aza-2'deoxycytidine reactivated the expression of RASSF1A. The experiment further indicated that the promoter methylation may result in the loss or low expression of the RASSF $1 A$ gene.

In summary, our results showed the promoter hypermethylation of the RASSF1A gene in a considerable proportion of primary sporadic breast cancer in Chinese women. The majority of RASSF 1A methylated cancers were found to have an absent or markedly reduced RASSF1A expression. The results are also consistent with other studies. Together, these findings suggest that RASSF1A promoter hypermethylation may also play an important role in breast tumor development in different nationalities.

\section{References}

1. Dammann R, Li C, Yoon JH, Chin PL, Bates S and Pfeifer GP: Epigenetic inactivation of a RAS association domain family protein from the lung tumour suppressor locus 3 p21.3. Nat Genet 25: 315-319, 2000.

2. Dammann R, Yang G and Pfeifer GP: Hypermethylation of the $\mathrm{CpG}$ island of Ras association domain family $1 \mathrm{~A}(R A S S F 1 A)$, a putative tumor suppressor gene from the $3 \mathrm{p} 21.3$ locus, occurs in a large percentage of human breast cancers. Cancer Res 61: 3105-3109, 2001 .

3. Burbee DG, Forgacs E, Zöchbauer-Müller S, Shivakumar L, Fong K, Gao B, Randle D, Kondo M, Virmani A, Bader S, Sekido Y, Latif F, Milchgrub S, Toyooka S, Gazdar AF, Lerman MI, Zabarovsky E, White M and Minna JD: Epigenetic inactivation of RASSF1A in lung and breast cancers and malignant phenotype suppression. J Natl Cancer Inst 93: 664-665, 2001.

4. Whang YM, Kim YH, Kim JS and Yoo DY: RASSF1A suppresses the c-Jun-NH2-kinase pathway and inhibits cell cycle progression. Cancer Res 65: 3682-3690, 2005.

5. Honorio S, Agathanggelou A, Schuermann M, Pankow W, Viacava P, Maher ER and Latif F: Detection of RASSF 1A aberrant promoter hypermethylation in sputum from chronic smokers and ductal carcinoma in situ from breast cancer patients. Oncogene 22: 147-150, 2003.

6. Tommasi S, Dammann R, Zhang Z, Wang Y, Liu L, Tsark WM, Wilczynski SP, Li J, You M and Pfeifer GP: Tumor susceptibility of Rassf1a knockout mice. Cancer Res 65: 92-98, 2005.

7. Burbee DG, Forgacs E and Zöchbauer-Müller S: Epigenetic inactivation of RASSF1A in lung and breast cancers malignant phenotype suppression. J Natl Cancer Inst 93: 691-699, 2001.

8. Dammann R, Takahashi T and Pfeifer GP: The CpG island of the novel tumor suppressor gene RASSF1A is intensely methylated in primary small cell lung carcinomas. Oncogene 20: 3563-3567, 2000 .
9. Agathanggelou A, Cooper WN and Latif F: Role of the Rasassociation domain family 1 tumor suppressor gene in human cancers. Cancer Res 65: 3497-3508, 2005.

10. Agathanggelou A, Honorio S, Macartney DP, Martinez A, Dallol A, Rader J, Fullwood P, Chauhan A, Walker R, Shaw JA, Hosoe S, Lerman MI, Minna JD, Maher ER and Latif F: Methylation-associated inactivation of RASSF1A from region 3 p21.3 in lung, breast and ovarian tumors. Oncogene 20: 1509-1518, 2001.

11. Yan PS, Shi H, Rahmatpanah F, Hsiau THC, Hsiau AHA, Leu YW, Liu JC and Huang THM: Differential distribution of DNA methylation within the RASSF $1 A \mathrm{CpG}$ island in breast cancer. Cancer Res 63: 6178-6186, 2003.

12. Shinozaki M, Hoon DS, Giuliano AE, Hansen NM, Wang HJ, Turner R and Taback B: Distinct hypermethylation profile of primary breast cancer is associated with sentinel lymph node metastasis. Clin Cancer Res 11: 2156-2162, 2005.

13. Geng C, Li X, Li Y, Shan B, Chen J, Fan Z and Wan S: Clinic pathologic significance of RASSF1A expression in human breast carcinoma. Chin J Cancer Prev Treat 13P: 1631-1634, 2006.

14. Herman JG, Graff JR, Myohanen S, Nelkin BD and Baylin SB: Methylation-specific PCR:A novel PCR assay for methylation status of CpG island. Proc Natl Acad Sci USA 93: 9821-9826, 1996.

15. Sasaki M, Anast J, Bassett W, Kawakami T, Sakuragi N and Dahiya R: Bisulfite conversion-specific and methylation-specific PCR: a sensitive technique for accurate evaluation of $\mathrm{CpG}$ methylation. Biochem Biophys Res Commun 309: 305-309, 2003.

16. Jones PA and Takai D: The role of DNA methylation in mammalian epigenetics. Science 293: 1068-1070, 2001.

17. Herman JG and Baylin SB: Gene silencing in cancer in association with promoter methylation. N Engl J Med 349: 2042-2054, 2003.

18. Schagdarsurengin U, Wilkens L, Steinemann D, Flemming P, Kreipe HH, Pfeifer GP, Schlegelberger B and Dammann R: Frequent epigenetic inactivation of the RASSF 1A gene in hepatocellular carcinoma. Oncogene 22: 1866-1871, 2003.

19. Zhong S, Yeo W, Tang MW, Wong N, Lai PB and Johnson PJ: Intensive hypermethylation of the CpG island of Ras association domain family $1 \mathrm{~A}$ in hepatitis B virus-associated hepatocellular carcinomas. Clin Cancer Res 9: 3376-3382, 2003.

20. Lehmann U, Wingen LU, Brakensiek K, Wedemeyer H, Becker T, Heim A, Metzig K, Hasemeier B, Kreipe H and Flemming P: Epigenetic defects of hepatocellular carcinoma are already found in non-neoplastic liver cells from patients with hereditary haemochromatosis. Hum Mol Genet 16: 1335-1342, 2007.

21. Liu L, Yoon JH, Dammann R and Pfeifer GP: Frequent hypermethylation of the RASSF 1A gene in prostate cancer. Oncogene 21: 6835-6840, 2002.

22. Kuzmin I, Gillespie JW, Protopopov A, Geil L, Dreijerink K, Yang Y, Vocke CD, Duh FM, Zabarovsky E, Minna JD, Rhim JS, Emmert-Buck MR, Linehan WM and Lerman MI: The RASSF1A tumor suppressor gene is inactivated in prostate tumors and suppresses growth of prostate carcinoma cells. Cancer Res 62: 3498-3502, 2002.

23. Lee JS, Lo PK, Fackler MJ, Argani P, Zhang Z, Garrett-Mayer E and Sukumar SA: Comparative study of Korean with Caucasian breast cancer reveals frequency of methylation in multiple genes correlates with breast cancer in young, ER, PR-negative breast cancer in Korean women. Cancer Biol Ther 6: 1114-1120, 2007. 